Shetabi, L. (2018) Event review: 3rd International Conference on Best Practices in World Heritage: Integral Actions. Mahon (Menorca, Balearic Islands, Spain) 2nd to 5th of May 2018. Journal of Community Archaeology and Heritage, 5(3), pp. 219-220. (doi: $\underline{10.1080 / 20518196.2018 .1487626)}$

There may be differences between this version and the published version. You are advised to consult the publisher's version if you wish to cite from it.

\title{
http://eprints.gla.ac.uk/163672/
}

Deposited on: 28 June 2018

Enlighten - Research publications by members of the University of Glasgow http://eprints.gla.ac.uk 
Event Review: 3rd International Conference on Best Practices in World Heritage: Integral Actions. Mahon (Menorca, Balearic Islands, Spain) 2nd to 5th of May 2018

by Linda Shetabi

The 3rd International Conference on Best Practices in World Heritage was held in Mahon 2nd to 5th of May. Alicia Castillo and Ángeles Querol (Complutense University of Madrid, Spain UCM), with their team of diligent students successfully organized the third in the series of conferences supported by the Island Council of Menorca. This year's theme was Integral Actions, aptly reflecting the interdisciplinary and dynamic nature of managing cultural landscapes. As more sites are inscribed to the World Heritage List, the boundaries of cultural landscapes become increasingly permeable, demanding integrated management approaches that respect the diversity of these landscapes and their local communities, while encouraging greater cooperation between a broader range of actors.

Stephan Döempke (World Heritage Watch, Germany) opened the conference with a keynote lecture on sustainable protection and sustainable development. Painting a sobering picture of the complexity of managing World Heritage sites (WHS) in Tajikistan, Ethiopia, China and Georgia, he described the lack of local infrastructure, resources, support and effective coordination between various local and international actors as challenges that impact the protection and management of sites, but notably impact the lives of resident communities. The need to engage local civic societies as well as volunteers, practitioners, and academics in designing and implementing management strategies that support sustainable development, while protecting WHS, was a message that underlined the sessions which followed. 
Presentations on Florence, Edinburgh, Bali, Moche Valley and Qhapaq Ñan, described the complex and often challenging interactions between government entities, civic societies and community members, and the role that NGOs play in addressing some of these challenges. With Renée Siván (Chief Curator, Tower of David Museum, Jerusalem) as moderator, the presentations were linked by Professor Nobuko Inaba's (Tsukuba University, Japan) lecture, describing the interplay of nature and culture in Japanese cultural sites, and the role of local government and communities in the sustainable management of these sites.

Professor Juan Luis Arsuaga (UCM) began the second day with a scientific look at the earliest examples of cultural heritage, inaugurating the scientific theme of the day. Moderated by Dr. Charles Musiba (University of Colorado, USA), the subsequent presentations revealed inextricable links between science, heritage conservation, public health and well-being. More than one presentation gave examples of recruiting citizen scientists as an effective strategy in fostering stronger civic engagement in protecting WHS. Perhaps the most significant lesson was reciprocal knowledge exchange between heritage scientists and local residents, whereby each fulfilled a complementary role in the holistic management and protection of sites.

The two next sessions primarily focused on integrating cultural heritage management with sustainable development. The presentations addressed the mutable nature of heritage values, challenges of balancing competing values, protection of intangible heritage as well as devising strategies that protected Outstanding Universal Values in the face of increasing economic pressures and ambitious political agendas. With Sonia Menendez (Cabinet of Archaeology, Cuba) and Manuel Gandara (National School of Conservation, Restoration and Museography, Mexico) as moderators, the stage was set for the first workshop which focused on economic considerations. Led by Lawrence Coben (University of Pennsylvania, USA) and Juan Ángel 
Martín Fernández (UCM), participants were grouped to review statistical and economic data of an undisclosed cultural site. The aim was to analyse the site from an economic perspective and devise appropriate management and protection strategies.

After two intense days, the visit to Menorca's Talayotic archaeological sites and tour of Ciutadela was a welcome reprieve despite the inclement weather. The rich archaeological sites across the island, and the display of local graffiti artists in support of Menorca's cultural landscape revealed an interesting contemporary bond between archaeology and community.

Following a traditional lunch in Ciutadela, the second conference workshop focused on environmental issues. Under the guidance of Peter Larsen (University of Lucerne, Switzerland) and Juan Guillermo (Universidad Católica de Pereira, Columbia), teams were tasked with identifying the challenges of their chosen site and devise best practices for its management and protection. The significance of this workshop was not necessarily in the outcomes, but in the robust interdisciplinary discussions between team members that led to more holistic approaches.

The final day of the conference was equally robust. David Barreiro (Spanish National Research Council) moderated presentations on socializing scientific knowledge, implementing effective interpretation schemes, utilizing technology and social media to connect larger audiences with conservation science, and addressing the challenges and opportunities of natural disasters in WHS. These discussions led to the final two workshops centred on best practices and Sustainable Development Goals.

In reviewing the workshop outcomes, it was evident that greater interdisciplinary and cross-sectoral cooperation between government entities, heritage sector and the wider civic community is required to devise strategies that both protect WHS and sustain local communities. 
With the growing interest in voluntary activism, conferences such as this provide a valuable platform for knowledge dissemination and exchange that lead the way for such cooperation.

\section{Notes on Reviewer}

Linda is a PhD Researcher in Urban Studies at the University of Glasgow (UK), School of Social and Political Sciences, conducting policy analysis on heritage conservation and urban planning within the context of the Sustainable Urban Development Agenda. She has an MSc in Architecture Conservation from University of Hong Kong, with a BA(Hons) in Art and Architecture History from University of California, Los Angeles, USA.

L.Shetabi.1@ research.gla.ac.uk 